University of Wollongong

Research Online

Australian Institute for Innovative Materials -

Papers

Australian Institute for Innovative Materials

2013

Hollow structured Li3VO4 wrapped with graphene nanosheets in situ prepared by one-pot template-free method as an anode for lithium-ion batteries

Yi Shi

University of Wollongong, ys551@uowmail.edu.au

Jia-Zhao Wang

University of Wollongong, jiazhao@uow.edu.au

Shulei Chou

University of Wollongong, shulei@uow.edu.au

David Wexler

University of Wollongong, davidw@uow.edu.au

Hui-Jun Li

University of Wollongong, huijun@uow.edu.au

See next page for additional authors

Follow this and additional works at: https://ro.uow.edu.au/aiimpapers

Part of the Engineering Commons, and the Physical Sciences and Mathematics Commons

Research Online is the open access institutional repository for the University of Wollongong. For further information contact the UOW Library: research-pubs@uow.edu.au 


\title{
Hollow structured Li3VO4 wrapped with graphene nanosheets in situ prepared by one-pot template-free method as an anode for lithium-ion batteries
}

\author{
Abstract \\ To explore good anode materials of high safety, high reversible capacity, good cycling, and excellent rate \\ capability, a Li3VO4 microbox with wall thickness of $40 \mathrm{~nm}$ was prepared by a one-pot and template-free \\ in situ hydrothermal method. In addition, its composite with graphene nanosheets of about six layers of \\ graphene was achieved. Both of them, especially the Li3V04/graphene nanosheets composite, show \\ superior electrochemical performance to the formerly reported vanadium-based anode materials. The \\ composite shows a reversible capacity of $223 \mathrm{mAh} \mathrm{g}-1$ even at $20 \mathrm{C}(1 \mathrm{C}=400 \mathrm{mAh} \mathrm{g}-1)$. After 500 \\ cycles at $10 \mathrm{C}$ there is no evident capacity fading.

\section{Keywords} \\ situ, prepared, hollow, one, structured, pot, template, free, method, anode, lithium, ion, batteries, li3vo4, \\ wrapped, graphene, nanosheets \\ Disciplines \\ Engineering | Physical Sciences and Mathematics

\section{Publication Details} \\ Shi, Y., Wang, J., Chou, S., Wexler, D., Li, H., Ozawa, K., Liu, H. \& Wu, Y. (2013). Hollow structured Li3VO4 \\ wrapped with graphene nanosheets in situ prepared by one-pot template-free method as an anode for \\ lithium-ion batteries. Nano Letters: a journal dedicated to nanoscience and nanotechnology, 13 (10), \\ 4715-4720.
}

\section{Authors}

Yi Shi, Jia-Zhao Wang, Shulei Chou, David Wexler, Hui-Jun Li, Kiyoshi Ozawa, Hua-Kun Liu, and Yu-Ping Wu 


\title{
Hollow Structured $\mathrm{Li}_{3} \mathrm{VO}_{4}$ Wrapped with Graphene
}

\section{Nanosheets in-situ prepared by One-pot Template-}

\section{free Method as Anode for Lithium-ion Batteries}

\author{
Yi Shi ${ }^{a, b}$, Jia-Zhao Wang ${ }^{b}$, Shu-Lei Chou ${ }^{b}$, David Wexler ${ }^{c}$, Hui-Jun Li ${ }^{d}$, Kiyoshi Ozawa ${ }^{e}, H u a-$ \\ Kun Liu ${ }^{b}$, Yu-Ping $W u^{a} *$
}

${ }^{a}$ New Energy and Materials Laboratory (NEML), Department of Chemistry \& Shanghai Key Laboratory of Molecular Catalysis and Innovative Materials, Fudan University, Shanghai 200433, China
${ }^{\mathrm{b}}$ Institute for Superconducting and Electronic Materials, University of Wollongong, Wollongong, Australia

${ }^{c}$ Electron Microscopy Centre, Innovation Campus, University of Wollongong, Australia

${ }^{\mathrm{d}}$ Faculty of Engineering, University of Wollongong, Wollongong, Australia

${ }^{\mathrm{e}}$ National Institute for Materials Science, Japan 
ABSTRACT: To explore good anode materials of high safety, high reversible capacity, good cycling and excellent rate capability, a $\mathrm{Li}_{3} \mathrm{VO}_{4}$ microbox with wall thickness of 40 $\mathrm{nm}$ was prepared by a one-pot and template-free in-situ hydrothermal method. In addition, its composite

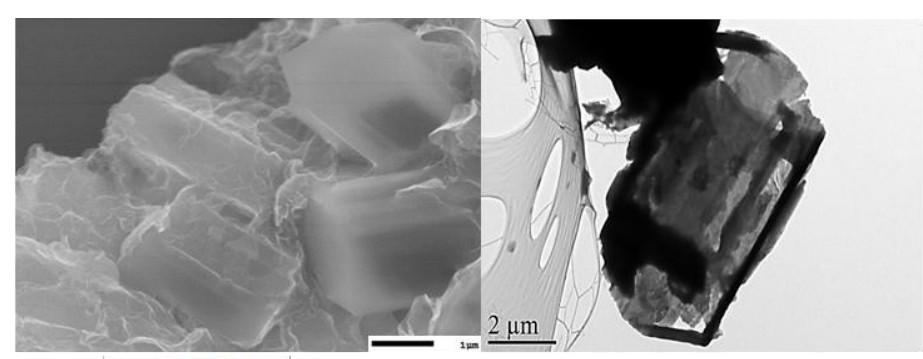

with graphene nanosheets of about 6 layers of graphene was achieved. Both of them especially the $\mathrm{Li}_{3} \mathrm{VO}_{4} /$ graphene nanosheets composite show superior electrochemical performance to the formerly reported vanadium-based anode materials. The composite shows a reversible capacity of $223 \mathrm{mAh} \mathrm{g}^{-1}$ even at $20 \mathrm{C}\left(1 \mathrm{C}=400 \mathrm{mAh} \mathrm{g}^{-1}\right)$. After 500 cycles at $10 \mathrm{C}$ there is no evident capacity fading.

\section{KEYWORDS:}

Lithium vanadium oxide; graphene; nanosheet; hollow structure; anode; lithium ion battery 
Developing a sustainable and renewable energy future has been one of the most important tasks for worldwide scientists to address increasing global energy consumption as well as the critical issue of climate change. Efficient energy storage systems are needed for the electricity generated from intermittent, renewable sources. ${ }^{1}$ Rechargeable lithium ion batteries have been commercially successful energy storage devices since $1991 .^{2}$ So far, there are three main anode materials: the alloy-type anodes materials such as $\mathrm{Si}$ - and $\mathrm{Sn}$-based alloys and their composites, ${ }^{3}$ the conversion reaction type ones such as transition metal oxides, ${ }^{4,5}$ and the intercalation/deintercalation type one such as graphite, Ti-based oxides, ${ }^{6}$ and layered V-based oxides. ${ }^{6,7}$ Although work on the alternatives to intercalation type anode materials has made important progress, graphite still remains the dominant commercial anode material. However, graphite has a small lithium diffusion coefficient and experiences large volume variation of $9 \%$ during the lithium intercalation/de-intercalation process. In addition, it has severe safety issues of dendritic lithium growth, due to its low potential (only about $0.2 \mathrm{~V}$ versus $\mathrm{Li}^{+} / \mathrm{Li}$ ). Especially at high rates, polarization would considerably lower its potential further, causing the birth of lithium dendrites and the consequent safety issues. Furthermore, the thick solid electrolyte interphase (SEI) layer on its surface could also introduce kinetic problems for fast charge and discharge. ${ }^{8} \mathrm{Li}_{4} \mathrm{Ti}_{5} \mathrm{O}_{12}$ has been found to change its structure negligibly during the discharge/charge process, and possesses good lithium ion mobility and a long and stable voltage plateau, together with low cost, environmental friendliness, and enhanced safety. ${ }^{8-10}$ Nevertheless, its potential is still relatively higher, about $1.6 \mathrm{~V}$ (versus $\mathrm{Li}^{+} / \mathrm{Li}$ ), thus halving the overall cell voltage and negating the benefits. The estimated energy density of lithium ion batteries based on $\mathrm{Li}_{4} \mathrm{Ti}_{5} \mathrm{O}_{12}$ anode (regarding both potential and capacity) does not exceed one third of that on graphite if they are coupled with a typical $4 \mathrm{~V}$ cathode. ${ }^{5}$ It was recently reported that $\mathrm{Li}$ can be intercalated into the layered transition metal oxide $\mathrm{LiVO}_{2},{ }^{6}$ but its major difficulty for application as an anode lies in the fast 
deterioration of the material. ${ }^{11-13}$ So, it would be of great interest to find a new intercalation anode with large capacity and appropriate intercalation potential. ${ }^{5}$

Recently, it was reported that $\mathrm{Li}_{3} \mathrm{VO}_{4}$

${ }^{+}$, lower than the potential of $\mathrm{Li}_{4} \mathrm{Ti}_{5} \mathrm{O}_{12}$ and higher than that of graphite. Its theoretical capacity is $394 \mathrm{mAh} \mathrm{g}^{-1}$, in accordance with $\mathrm{x}=2$ in $\mathrm{Li}_{3+\mathrm{x}} \mathrm{VO}_{4}$. Combined with the low and safe voltage, $\mathrm{Li}_{3} \mathrm{VO}_{4}$ features a large specific capacity and low cost. It might act as a new intercalation anode for the lithium ion battery. ${ }^{5}$ Despite these advantages, the practical use of this material still faces some barriers. $\mathrm{Li}_{3} \mathrm{VO}_{4}$ requires further modifications to overcome certain limitations, such as low electronic conductivity, which is quite lower compared to its ionic conductivity, and this may cause large resistance polarization and poor rate capability. Thus, reducing the particle size and hybridization with electronically conductive materials are necessary for this material to be suitable for future use. ${ }^{5}$

The properties of inorganic hollow structures can be well tuned by tailoring their morphology and crystallinity. ${ }^{14-16}$ However, it is a great challenge to develop feasible methods for the one-pot, template-free, solution synthesis of single-crystalline particles with well-defined non-spherical morphologies. ${ }^{17}$ Here, we reported the preparation of a composite of hollow $\mathrm{Li}_{3} \mathrm{VO}_{4}$ microboxes with a wall thickness of about $40 \mathrm{~nm}$ wrapped by graphene nanosheets (LVO/G). When the LVO/G composite is used as anode material for lithium ion batteries, it offers significant improvements in capacity, rate capability and cycling life compared to the reported vanadiumbased anode materials. ${ }^{5,13}$ 
Scheme 1 Schematic illustration summarizing all the major morphological changes involved in the synthesis of $\mathrm{LVO} / \mathrm{G}$ by corrosive etching: a) commercial $\mathrm{V}_{2} \mathrm{O}_{3}$ microrod; b) pitting at several specific sites on the surface of such a microrod, where the $\mathrm{O}_{2}$ dissolved in the solvent and the functional groups of graphene oxide have oxidized the $\mathrm{V}_{2} \mathrm{O}_{3}$; c) cross-section of hollow structure after further etching of the interior of the rod and its covering with $\mathrm{Li}_{3} \mathrm{VO}_{4}$ precipitate; d) subsequent hollowing of the rod; e) formation of a completely enclosed $\mathrm{Li}_{3} \mathrm{VO}_{4}$ microbox wrapped with graphene nanosheets.

At first, graphene oxide (GO) was prepared according to the method reported by Hummers from $\mathrm{p} \quad \mathrm{p} d(\mathrm{Ad}, \mathrm{p} d,<2 \mu, \quad \quad)^{17}$ Then the LVO/G composite was prepared by an in-situ one-step hydrothermal process as shown in Scheme 1. In a typical synthesis, a suitable amount of $\mathrm{GO}$, hydrazine hydrate, $1.688 \mathrm{~g} \mathrm{LiOH}, 0.304 \mathrm{~g} \mathrm{~V}_{2} \mathrm{O}_{3}(>99.0 \%$, Sigma-Aldrich), and de-ionized $\mathrm{H}_{2} \mathrm{O}$ were mixed together for $2 \mathrm{~h}$ using an ultrasonic probe, 
which was followed by vigorous magnetic stirring at room temperature for $0.5 \mathrm{~h}$. The resultant mixture was then transferred to an autoclave and kept in an oven at $180{ }^{\circ} \mathrm{C}$ for $40 \mathrm{~h}$ under a vacuum pressure of $0.1 \mathrm{MPa}$. The product was washed with de-ionized water, anhydrous ethanol, and acetone several times and dried at $80{ }^{\circ} \mathrm{C}$ in a vacuum oven for $4 \mathrm{~h}$. For comparison, $\mathrm{Li}_{3} \mathrm{VO}_{4}$ microboxes was also prepared using the same procedure without graphene oxide and hydrazine hydrate, and graphene was obtained by the reduction of grapheen oxide with hydrazine hydrate. As to the detailed formation mechanism of the microboxes (Scheme 1), the supporting information (Figures S1 and S2) can be referred. The main action is due to the hollowing of the initial microrods by an oxygen-engaged oxidation process from $\mathrm{V}_{2} \mathrm{O}_{3}$ into $\mathrm{VO}_{4}{ }^{3-}$, ${ }^{14}$ and the precipitating of the soluble $\mathrm{VO}_{4}{ }^{3-}$ anions on the surface of the $\mathrm{V}_{2} \mathrm{O}_{3}$ cubes as $\mathrm{Li}_{3} \mathrm{VO}_{4}{ }^{18}$

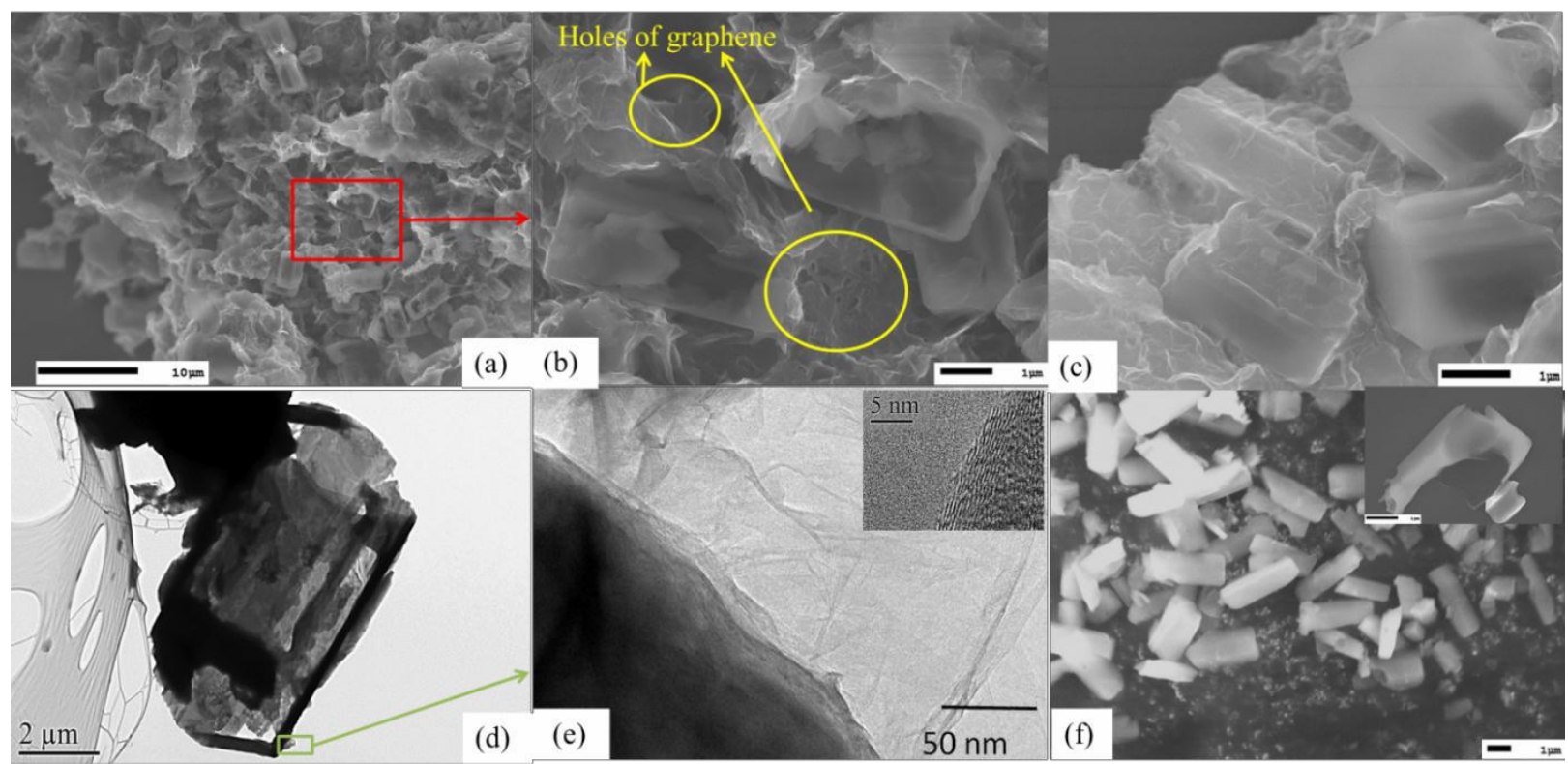

Figure 1 Electronic micrographs of LVO/G composite measured by a field emission scanning electron microscopy (FE-SEM: JEOL JSM-7500FA; TEM: JEOL 2011 high resolution instrument): (a) FESEM secondary electron micrograph of large area of LVO/G; (b) FESEM micrograph of the area indicated by the rectangle marked with red lines in Figure 1(a); (c) FESEM micrograph of LVO/G; (d) TEM micrograph of hollow LVO/G; (e) graphene region 
attached to $\mathrm{Li}_{3} \mathrm{VO}_{4}$ (lower right) with the inset of HRTEM micrograph of edge of graphene, revealing contrast from C-type fringes, and (f) FESEM micrograph of LVO with the inset showing a broken $\mathrm{Li}_{3} \mathrm{VO}_{4}$ microbox.

Electronic micrographs (Figure 1) of the LVO/G composite indicates that the sample comprises of $\mathrm{Li}_{3} \mathrm{VO}_{4}$ microboxes and graphene nanosheets. The average size of the $\mathrm{Li}_{3} \mathrm{VO}_{4}$ microboxes is $\mathrm{u} \mathrm{d} 2 \mu$ in length, $800 \mathrm{~nm}$ in width and $500 \mathrm{~nm}$ in height. Its wall thickness is around $40 \mathrm{~nm}$ (Figure 1f). The hollow structure of the $\mathrm{Li}_{3} \mathrm{VO}_{4}$ microboxes and holes between the graphene nanosheets can easily be filled with electrolyte, which is expected to offer rapid routes for both $\mathrm{Li}^{+}$ion and electron transportation. The surface of the hollow LVO microboxes is wrapped with graphene nanosheets of about 6 layers in thickness (Figures 1d and 1e). It should be emphasized that even after a long period of sonication during the preparation of the FESEM and TEM specimens, the graphene nanosheets are still anchored on the surface of the $\mathrm{Li}_{3} \mathrm{VO}_{4}$ microboxes, suggesting that their interaction is strong. ${ }^{19}$
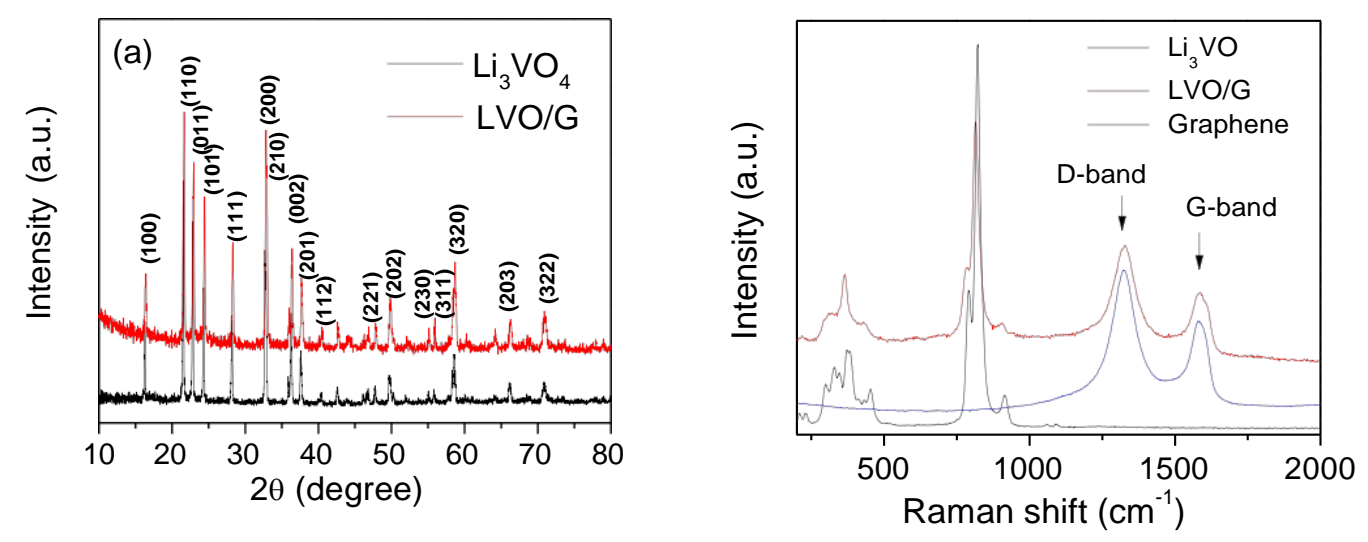

Figure 2 (a) XRD patterns of the prepared $\mathrm{Li}_{3} \mathrm{VO}_{4}$ microboxes and the $\mathrm{LVO} / \mathrm{G}$ composite which were measured by $\mathrm{u} \quad \mathrm{GBC}$ MMA $\mathrm{u} \quad \mathrm{Cu} \mathrm{K} \alpha$ radiation and a graphite monochromator. Data were collected from powder samples at a scanning rate of $3^{\circ} \mathrm{min}^{-1} \mathrm{f} \quad 2 \theta$ 
in the range of $10^{\circ}-80^{\circ}$; and (b) Raman spectra of the graphene, the $\mathrm{Li}_{3} \mathrm{VO}_{4}$ microboxes, and the LVO/G composite obtained by using a Jobin Yvon HR800.

X-ray diffraction (XRD) patterns for the $\mathrm{Li}_{3} \mathrm{VO}_{4}$ microboxes and the $\mathrm{LVO} / \mathrm{G}$ composite (Figure 2a) show that most diffraction lines can be indexed to the orthorhombic $\mathrm{Li}_{3} \mathrm{VO}_{4}$ phase (JCPDS No. 38-1247) with the lattice parameters $a=5.447 \AA, b=6.327 \AA, c=4.948 \AA$, and $\alpha=\beta=\gamma=$ $90^{\circ}$. Diffraction peaks which might appear for graphene are absent, most likely because they are below the limits of detection by XRD, or the graphene (002) peak is eclipsed by the $\mathrm{Li}_{3} \mathrm{VO}_{4}(111)$ one. Another reason is that the layers of graphene sheets is too few, about 6 as the above mentioned, and their diffraction intensity is very weak. Raman spectra (Figure 2b) indicate the existence of $\mathrm{Li}_{3} \mathrm{VO}_{4}$ and graphene in the composite. The bands in the range of $1200-1460 \mathrm{~cm}^{-1}$ and $1470-1730 \mathrm{~cm}^{-1}$ are attributed to the D-band (K-point phonons of $\mathrm{A}_{1 \mathrm{~g}}$ symmetry) and G-band ( $\mathrm{E}_{2 \mathrm{~g}}$ phonons of $\mathrm{C} \mathrm{sp}{ }^{2}$ atoms) of graphene. The broadening of the $\mathrm{D}$ and $\mathrm{G}$ bands with a strong $\mathrm{D}$ line indicates localized in-plane $\mathrm{sp}^{2}$ domains and disordered graphitic crystal stacking of the graphene nanosheets. The peak intensity ratio between the 1333 and $1592 \mathrm{~cm}^{-1}$ peaks $\left(\mathrm{I}_{\mathrm{D}} / \mathrm{I}_{\mathrm{G}}\right)$ generally provides a useful index about the degree of crystallinity of various carbon materials, i.e., the smaller the $I_{D} / I_{G}$ ratio, the higher the degree of ordering in the carbon material. ${ }^{20}$ The $\mathrm{I}_{\mathrm{D}} / \mathrm{I}_{\mathrm{G}}$ values of the graphene and the $\mathrm{LVO} / \mathrm{G}$ composite are 1.633 and 1.638 , respectively, indicating that the graphene nanosheets are well retained even after their wrapping on the $\mathrm{Li}_{3} \mathrm{VO}_{4}$ microboxes. ${ }^{21,33}$ The amount of graphene in the LVO/G composite was estimated to be approximately $10.5 \mathrm{wt}$ \% from the thermogravimetric analysis (Figure S3). 

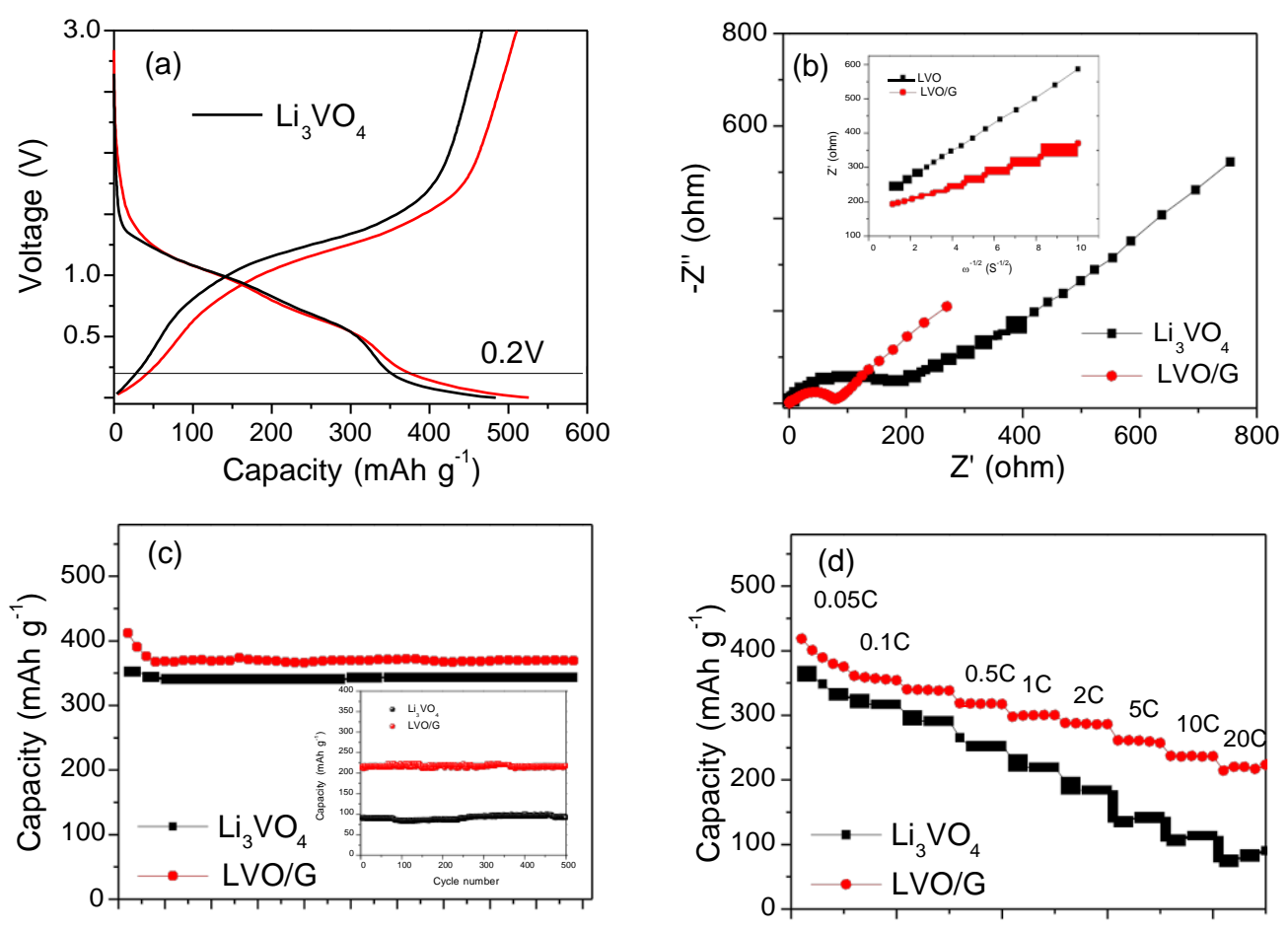

Cycle number

Cycle number

Figure 3 Electrochemical performance of the $\mathrm{Li}_{3} \mathrm{VO}_{4}$ and the $\mathrm{LVO} / \mathrm{G}$ composite tested by using the electrodes prepared by pasting the mixture of the $\mathrm{Li}_{3} \mathrm{VO}_{4}$ or $\mathrm{LVO} / \mathrm{G}$ anode material, carbon black and sodium carboxymethyl cellulose (CMC) in a weight ratio of 75: 20: 5 on a copper foil followed by a drying in a vacuum oven at $150{ }^{\circ} \mathrm{C}$ for $2 \mathrm{~h}$. CR 2032 coin-type cells were assembled in an Ar-filled glove box (Mbraun, Unilab, Germany) using lithium metal foil as the counter and reference electrode and $1 \mathrm{M} \mathrm{LiPF}_{6}$ solution in ethylene carbonate/diethyl carbonate as the electrolyte: (a) typical discharge and charge profiles at the current density of $20 \mathrm{~mA} \mathrm{~g}^{-1}$ between the voltage range of 0 and $3 \mathrm{~V}$ measured by a Land Battery Tester; (b) Nyquist plots of the anodes $\mathrm{f}$ $\mathrm{p} \quad \mathrm{f} \quad \mathrm{p}$ x $\quad \mathrm{pd}$ $\mathrm{u} \quad \omega^{-1 / 2}$ at an anodic potential of $0.75 \mathrm{~V}$ ( $\mathrm{vs} \mathrm{Li}^{+} / \mathrm{Li}$ ) (inset) (Biologic VMP3 electrochemical workstation, the AC amplitude was $5 \mathrm{mV}$, and the frequency range applied was $0.01 \mathrm{~Hz}$ to $100 \mathrm{kHz}$ ); (c) cycling performance at the current density of $20 \mathrm{~mA} \mathrm{~g}^{-1}$ between the voltage range of 0.2 and $3 \mathrm{~V}$ and the 
inset is their cycling performance at $10 \mathrm{C}\left(4 \mathrm{~A} \mathrm{~g}^{-1}\right)$; and (d) rate performance between the voltage range of 0.2 and $3 \mathrm{~V}$.

The electrochemical performance of the $\mathrm{Li}_{3} \mathrm{VO}_{4}$ microboxes and the $\mathrm{LVO} / \mathrm{G}$ composite is shown in Figure 3. The gentle slope in the charge/discharge curves of the LVO/G composite may be attributed to the graphene. Both of them show a great overlapping above $0.2 \mathrm{~V}$ in the charge/discharge curves (Figure 3a). The charge (reversible) capacity of the LVO/G composite is $511 \mathrm{mAh} \mathrm{g}^{-1}$ (based on the weight of the composite) between 0 and $3.0 \mathrm{~V}, 44 \mathrm{mAh} \mathrm{g}^{-1}$ higher than that of the $\mathrm{Li}_{3} \mathrm{VO}_{4}$ microboxes, and the main capacity is situated between 0.2 and $2.0 \mathrm{~V}$. These data are much higher than those of the reported. ${ }^{5,13}$ The main capacity is situated at about $1 \mathrm{~V}$, which is consistent with their cyclic voltammograms (Figure S4). In addition, the $\mathrm{Li}_{3} \mathrm{VO}_{4}$ also shows a discharge platform below $0.2 \mathrm{~V}$, which makes the whole charge capacity reach 467 mAh $\mathrm{g}^{-1}$, much higher than that of the commercial graphite. The comparison of the discharge/charge profiles between different voltage range is shown in Figure S5. Considering that the amount of graphene is $10.5 \mathrm{wt} . \%$, the above comparison indicates that the contribution of graphene to capacity is not small, which will be about $440 \mathrm{mAh} \mathrm{g}^{-1}$ for the graphene nanosheets. This is similar to that for the reported amorphous carbon, whose voltage is ranging from 0 to 3.0 V. ${ }^{24}$ As a result, the intercalation and de-intercalation reactions during the charge and discharge process can be shown as equation (1):

$$
\mathrm{Li}_{3} \mathrm{VO}_{4}+\mathrm{x} \mathrm{Li}^{+}+\mathrm{x} \mathrm{e}^{-} \rightleftharpoons \mathrm{Li}_{3+\mathrm{x}} \mathrm{VO}_{4}(0 \leq \mathrm{x} \leq 2)
$$

The Nyquist plots (EIS spectra) show two compressed semicircles in the high to medium frequency range of each spectrum, which describe the charge transfer resistance $\left(R_{\mathrm{ct}}\right)$ for these electrodes, and an approximately $45^{\circ}$ inclined line in the low-frequency range, which could be considered as Warburg impedance $\left(Z_{\mathrm{W}}\right)$, which is associated with the lithium-ion diffusion in the 
bulk of the active material. The first compressed semicircle is related to the SEI film, and the high-frequency intercept of the second semicircle is related to the uncompensated resistance $\left(R_{\mathrm{u}}\right)$, while the diameter of the second semicircle is related to the charge transfer resistance $\left(R_{\mathrm{ct}}\right){ }^{22}$ After simulating the second compressed semicircle for both samples, the values of $R_{\mathrm{ct}}$ for the $\begin{array}{llllllllllll}\mathrm{Li}_{3} \mathrm{VO}_{4} & \mathrm{~d} & \mathrm{O} & \mathrm{g} & \mathrm{d} & \mathrm{f} & \mathrm{u} & \mathrm{d} & 2 & \mathrm{~d} 8 & \Omega & \mathrm{p}\end{array}$ The lithium diffusion coefficient can also be calculated by using the following equation:

$$
D=R^{2} T^{2} / 2 A^{2} n^{4} F^{4} C^{2} \sigma^{2}
$$

where $R$ is the gas constant, $T$ is the absolute temperature, $A$ is the surface area of the anode (1 $\mathrm{cm}^{2}$ ), $n$ is the number of electrons transferred in the half-reaction for the redox couple, $F$ is the Faraday constant, $C$ is the concentration of $\mathrm{Li}$ ions in the solid $\left(2.94 \times 10^{-2} \mathrm{~mol} \mathrm{~cm}{ }^{-3}\right), D$ is the diffusion coefficient $\left(\mathrm{cm}^{2} \mathrm{~s}^{-1}\right)$, and $\sigma$ is the Warburg factor, which is relative to $Z_{\mathrm{re}}$. From the slope of the lines in the inset of Figure $3 b \sigma$ can be obtained. ${ }^{23}$

$$
Z_{\mathrm{re}}=R_{\mathrm{D}}+R_{\mathrm{L}}+\sigma \omega^{-1 / 2}
$$

According to the linear fitting, the slope of the real part of the complex impedance versus $\omega^{-1 / 2}$ at the potential of $0.75 \mathrm{~V}\left(\mathrm{vs} . \mathrm{Li} / \mathrm{Li}^{+}\right.$) for the $\mathrm{Li}_{3} \mathrm{VO}_{4}$ and $\mathrm{LVO} / \mathrm{G}$ electrodes after 5 cycles is 39.3 and 20.1, respectively. The lithium diffusion coefficients at $25{ }^{\circ} \mathrm{C}$ were calculated to be $2.63 \times$ $10^{-14}$ and $1.02 \times 10^{-13} \mathrm{~cm}^{2} \mathrm{~s}^{-1}$ for the $\mathrm{Li}_{3} \mathrm{VO}_{4}$ and the $\mathrm{LVO} / \mathrm{G}$ composite, respectively. These results show that the $\mathrm{LVO} / \mathrm{G}$ composite presents smaller charge transfer resistance and higher lithium diffusion coefficient, which are favorable for rapid charge and discharge.

After the first few cycles, the electrode reactions show high reversibility (Figure 3c). The charge capacity of the third cycle of the $\mathrm{Li}_{3} \mathrm{VO}_{4}$ between the voltage range of 0.2 and $3 \mathrm{~V}$ is $345 \mathrm{mAh} \mathrm{g}^{-}$ ${ }^{1}$, and it keeps very stable after 50 cycles. The cycling performance is superior to that of another newly reported vanadium-based insertion anode material, $\mathrm{LiVO}_{2}$, whose capacity dropped from $350 \mathrm{mAh} \mathrm{g}^{-1}$ to $100 \mathrm{mAh} \mathrm{g}{ }^{-1}$ after 10 cycles, ${ }^{6,11,12}$ and that of the reported $\mathrm{Li}_{3} \mathrm{VO}_{4},{ }^{5,13}$ whose 
capacity faded from the crack of crystal. In the case of the $\mathrm{Li}_{3} \mathrm{VO}_{4} /$ graphene composite, it shows an even higher capacity. The charge capacity of the LVO/G composite in the third cycle is 378 $\mathrm{mAh} \mathrm{g}^{-1}$ and does not fade evidently after 50 cycles, which is very near to its theoretical capacity, $394 \mathrm{mAh} \mathrm{g}^{-1}$. After long cycling at high rate (10C), the capacity is still stable. The good retention of capacity can also be proved by the stable EIS spectra and tact SEM micrographs after cycling (Figure S6).

To compare the rate capability, the $\mathrm{C}$ rate is based only on the $\mathrm{Li}_{3} \mathrm{VO}_{4}$ and $1 \mathrm{C}$ is $400 \mathrm{~mA} \mathrm{~g}^{-1}$. The $\mathrm{Li}_{3} \mathrm{VO}_{4}$ can retain a reversible capacity of $87 \mathrm{mAh} \mathrm{g}^{-1}$ at $20 \mathrm{C}$. In contrast, the $\mathrm{LVO} / \mathrm{G}$ composite exhibits an obviously much improved performance over the $\mathrm{Li}_{3} \mathrm{VO}_{4}$ (Figure $3 \mathrm{~d}$ ). A high charge capacity of $223 \mathrm{mAh} \mathrm{g}^{-1}$ was obtained for the LVO/G composite at the current density of $20 \mathrm{C}$, which is $136 \mathrm{mAh} \mathrm{g}^{-1}$ higher than that of the LVO. These results are also superior to the reported vanadium-based anode materials, ${ }^{5,13}$ and also superior to those of graphite.

The improvement in the electrochemical performance of the $\mathrm{Li}_{3} \mathrm{VO}_{4}$ over the reported vanadiumbased anode materials can be due to several factors. First, the cavities or holes in the hollow structure may provide extra space for the storage of lithium ions like in carbons, ${ }^{24}$ which is beneficial for enhancing the specific capacity, and this is the main reason the reversible capacities of the $\mathrm{Li}_{3} \mathrm{VO}_{4}$ microboxes and the $\mathrm{LVO} / \mathrm{G}$ composite are higher than the theoretic value of $\mathrm{Li}_{3} \mathrm{VO}_{4}$. Second, the hollow structure is often associated with larger surface area, which provides more sites for lithium insertion-desertion, leading to good charge and discharge performance at large current densities. ${ }^{25}$ Third, the nanometer $(40 \mathrm{~nm})$ wall effectively reduces the diffusion distance for lithium ions, leading to better rate capabilities. Fourth, the void space in the hollow structures buffers the local volume change during lithium insertion-desertion and is able to alleviate the problem of pulverization and aggregation of the electrode material, hence keeping structural stability during cycling. ${ }^{25,26}$ 
In the case of the $\mathrm{LVO} / \mathrm{G}$ composite, its superior electrochemical performance is ascribed to the wrapped graphene nanosheets. First, it provides higher electronic conductivity leading to the reduced charge transference resistance. ${ }^{21,22}$ Second, ${ }^{27,28}$ the high chemical diffusivity of Li on a graphene plane favors the transportation of lithium ions. ${ }^{21,29-35}$ Third, the grapene nanosheets have the open and flexible porous structure favoring the emission the strain/stress and the retaining good structural stability during cycling. ${ }^{32,35}$

In summary, a composite of $\mathrm{Li}_{3} \mathrm{VO}_{4}$ /graphene has been synthesized by a novel rapid one-step insitu hydrothermal method. The resultant composite reveals a unique morphology, in which homogeneous hollow structured $\mathrm{Li}_{3} \mathrm{VO}_{4}$ microboxes of $40 \mathrm{~nm}$ wall thickness are wrapped with porous graphene nanoosheets. The hollow structure could relax the stress/strain of $\mathrm{Li}^{+}$ insertion/de-insertion, increase the surface area of the materials, provide extra space for the storage of lithium ions, and reduce the effective diffusion distance for lithium ions. As a result, improved capacity, rate capability and cycling performance have been achieved for the $\mathrm{Li}_{3} \mathrm{VO}_{4}$ microboxes. Furthermore, this graphene-wrapped nano-architecture provides high electronic conductivity for both facile mass transfer and facile charge transfer, and good structural stability for the $\mathrm{Li}_{3} \mathrm{VO}_{4}$ microboxes. The $\mathrm{Li}_{3} \mathrm{VO}_{4} /$ graphene composite has superior electrochemical performance such as high capacity, stable cycling life, and exceptional good rate capability. Therefore, the $\mathrm{Li}_{3} \mathrm{VO}_{4} /$ graphene nanosheets composite is a promising anode candidate for the development of high-performance, low-cost, and advanced lithium batteries.

\section{ASSOCIATED CONTENT}

Supporting Information. Materials, Methods and addition supplemented figures. These materials are available free of charge via the Internet at http://pubs.acs.org. 


\section{AUTHOR INFORMATION \\ Corresponding Author \\ E-mail: wuyp@fudan.edu.cn}

\section{Author Contribution}

The manuscript was written through contributions of all authors. All authors have given approval to the final version of the manuscript.

Notes

The authors declare no competing financial interest.

\section{ACKNOWLEDGMENT}

Financial support from an Australian Research Council (ARC) Discovery Project (DP100103909) and the National Natural Science Foundation of China (NSFC) (21073046) is greatly appreciated. Many thanks also go to Dr. Tania Silver for critical reading of the manuscript.

\section{REFERENCES}

1. Yu, G.; Hu, L.; Vosgueritchian, M.; Wang, H.; Xie, X.; McDonough, J. R.; Cui, X.; Cui, Y.; Bao, Z. Nano Lett. 2011, 11, (7), 2905-2911.

2. Cui, L.-F.; Ruffo, R.; Chan, C. K.; Peng, H.; Cui, Y. Nano Lett. 2008, 9, (1), 491-495.

3. Manthiram, A. J. Phys. Chem. Lett. 2011, 2, (3), 176-184.

4. Bruce, P. G.; Scrosati, B.; Tarascon, J. M. Angew. Chem. Int. Ed. 2008, 47, (16), 29302946. 
5. Li, H.; Liu, X.; Zhai, T.; Li, D.; Zhou, H. Adv. Energy Mater. 2012, 3, (4), 428-432.

6. Armstrong, A. R.; Lyness, C.; Panchmatia, P. M.; Islam, M. S.; Bruce, P. G. Nat. Mater. 2011, 10, (3), 223-229.

7. Malini, R.; Uma, U.; Sheela, T.; Ganesan, M.; Renganathan, N. Ionics 2009, 15, (3), 301307.

8. (a) Wang, G.J.; Gao, J.; Fu, L.J.; Zhao, N.H.; Wu, Y.P.; Takamura, T. J. Power Sources 2007, 174, 1109-1112; and (b) Kim, H.-K.; Bak, S.-M.; Kim, K.-B. Electrochem. Commun. 2010, 12, (12), 1768-1771.

9. Ohzuku, T.; Ueda, A.; Yamamoto, N. J. Electrochem. Soc. 1995, 142, (5), 1431-1435.

10. Chen, J.; Yang, L.; Fang, S.; Hirano, S.-i.; Tachibana, K. J. Power Sources 2011.

11. Song, J. H.; Park, H. J.; Kim, K. J.; Jo, Y. N.; Kim, J.-S.; Jeong, Y. U.; Kim, Y. J. J. Power Sources 2010, 195, (18), 6157-6161.

12. Kim, W.-T.; Jeong, Y. U.; Choi, H. C.; Kim, Y. J.; Song, J. H.; Lee, H.; Lee, Y. J. J. Appl. Electrochem. 2011, 41, (7), 803-808.

13. Kim, W.-T.; Jeong, Y. U.; Lee, Y. J.; Kim, Y. J.; Song, J. H. J. Power Sources 2013, http://dx.doi.org/10.1016/j.jpowsour.2013.01.163.

14. Lu, C.; Qi, L.; Yang, J.; Wang, X.; Zhang, D.; Xie, J.; Ma, J. Adv. Mater. 2005, 17, (21), 2562-2567.

15. Lou, X. W.; Wang, Y.; Yuan, C.; Lee, J. Y.; Archer, L. A. Adv. Mater. 2006, 18, (17), 2325-2329. 
16. Yang, J.; Qi, L.; Lu, C.; Ma, J.; Cheng, H. Angew. Chem. Int. Ed. 2005, 44, (4), 598-603.

17. Laura, J.; Franklin, K.; Huang, J. J. Am. Chem. Soc 2009, 131, 1043.

18. Xiong, Y.; Wiley, B.; Chen, J.; Li, Z. Y.; Yin, Y.; Xia, Y. Angew. Chem. Int. Ed. 2005, 44, (48), 7913-7917.

19. Wu, Z.-S.; Ren, W.; Wen, L.; Gao, L.; Zhao, J.; Chen, Z.; Zhou, G.; Li, F.; Cheng, H.-M. ACS Nano 2010, 4, (6), 3187-3194.

20. Wu, X. L.; Jiang, L. Y.; Cao, F. F.; Guo, Y. G.; Wan, L. J. Adv. Mater. 2009, 21, (25-26), 2710-2714.

21. (a) Tang, W.; Wang, X.J.; Hou, Y.Y.; Li, L.L.; Sun, H.; Zhu, Y.S.; Bai, Y.; Wu, Y.P.; Zhu, K.; van Ree, T. J. Power Sources, 2012, 198, (2), 308-311; and (b) Wang, L.; Wang, H.; Liu, Z.; Xiao, C.; Dong, S.; Han, P.; Zhang, Z.; Zhang, X.; Bi, C.; Cui, G. Solid State Ionics 2010, 181, (37), 1685-1689.

22. Murugan, A. V.; Muraliganth, T.; Manthiram, A. J. Electrochem. Soc. 2009, 156, (2), A79-A83.

23. Chou, S. L.; Wang, J.; Liu, H.; Dou, S. X. J. Phys. Chem. C 2011, 115, (32), 1622016227.

24. Wu, Y.P.; Wan, C.R.; Jiang, C.Y.; Fang, S.B.; Jiang, Y.Y. Carbon 1999, 37, (12), 19011908. 
25. (a) Tang, W.; Hou, Y.Y.; Wang, F.X.; Liu, L.L.; Wu, Y.P.; Zhu, K. Nano Lett. 2013, 13, (5), 2036 - 2040; and (b) Qu, Q.T.; Fu, L.J.; Zhan, X.Y.; Samuelis, D.; Li, L.; Guo, W.L.; Li, Z.H.; Wu, Y.P.; Maier, J. Energy Environ. Sci. 2011, 4, (10), 3985 - 3990.

26. (a) Lou, X. W.; Li, C. M.; Archer, L. A. Adv. Mater. 2009, 21, (24), 2536-2539; and (b) Lou, X. W. D.; Archer, L. A.; Yang, Z. Adv. Mater. 2008, 20, (21), 3987-4019.

27. Geim, A. K.; Novoselov, K. S. Nat. Mater. 2007, 6, (3), 183-191.

28. Wang, J.-Z.; Lu, L.; Choucair, M.; Stride, J. A.; Xu, X.; Liu, H.-K. J. Power Sources 2011, 196, (16), 7030-7034.

29. Persson, K.; Sethuraman, V. A.; Hardwick, L. J.; Hinuma, Y.; Meng, Y. S.; van der Ven, A.; Srinivasan, V.; Kostecki, R.; Ceder, G. J. Phys. Chem. Lett. 2010, 1, (8), 1176-1180.

30. Uthaisar, C.; Barone, V. Nano Lett. 2010, 10, (8), 2838-2842.

31. Wu, Z.-S.; Ren, W.; Xu, L.; Li, F.; Cheng, H.-M. ACS Nano 2011, 5, (7), 5463-5471.

32. Wang, H.; Yang, Y.; Liang, Y.; Robinson, J. T.; Li, Y.; Jackson, A.; Cui, Y.; Dai, H. Nano Lett. 2011, 11 (7), 2644-2647.

33. Wang, D.; Choi, D.; Li, J.; Yang, Z.; Nie, Z.; Kou, R.; Hu, D.; Wang, C.; Saraf, L. V.; Zhang, J. ACS Nano 2009, 3, (4), 907-914.

34. Sun, Y.; Wu, Q.; Shi, G. Energ. Environ.Sci. 2011, 4, (4), 1113-1132.

35. Shi, Y.; Chou, S.-L.; Wang, J.-Z.; Wexler, D.; Li, H.-J.; Liu, H.-K.; Wu, Y. J. Mater. Chem. 2012, 22, (32), 16465-16470. 